\title{
RESEARCH PAPER \\ Sustainable intensification of quinoa production in peri-urban environments in western Washington state utilizing transplant vs. direct-seed methods
}

\author{
Kristofor Ludvigson, John P. Reganold, and Kevin M. Murphy \\ Washington State University, Department of Crop and Soil Sciences. Washington, USA
}

\begin{abstract}
K. Ludvigson, J.P. Reganold, and K.M. Murphy. 2019. Sustainable intensification of quinoa production in peri-urban environments in western Washington state utilizing transplant vs. direct-seed methods. Cien. Inv.Agr. 46(2): 100-112. As a developing alternative crop in both urban and rural environments in the Pacific Northwest, quinoa (Chenopodium quinoa Willd.) is predominantly sown using direct-seeding technology on small- to large-scale farms. However, the utilization of transplant methodology could allow for earlier planting dates, improved weed control, and quicker maturation. Many urban farmers and gardeners are experienced and equipped to utilize transplant technology and would potentially be quick to adopt this practice. Following a pilot study in 2015, an experiment was conducted in 2016 that compared transplanting and direct-seeding on two farms in the Olympic Peninsula of western Washington state. With transplant and direct-seed treatments at each location, three quinoa varieties were planted at early, mid, and late planting dates. Here, we report that transplanted quinoa possessed higher survival rates, was quicker to reach later developmental stages, and produced higher yields than direct-seeded quinoa. Transplants were more branched and shorter than direct-seeded quinoa plants; however, they also experienced higher rates of lodging. As the planting dates progressed, lodging decreased, and seed yields increased in the transplanted quinoa across all three varieties compared to the direct-seeded quinoa. The utilization of transplants could provide quinoa growers in urban and peri-urban settings with an improved production method.
\end{abstract}

Keywords: Agroecology, crop diversity, direct-seeding, peri-urban agriculture, planting date, quinoa, transplanting, yield.

\section{Introduction}

Quinoa (Chenopodium quinoa Willd.) has been cultivated in the Andean region of South America for over 7,000 years (Garcia, 2003; Murphy et al., 2018). Traditional production within this region has focused on the utilization of multiple quinoa

Received Apr 21, 2019. Accepted Jul 17, 2019.

Corresponding author: kmurphy2@wsu.edu cultivars within a single crop as well as the use of polyculture and crop rotations that include potato, barley, beans, and kaniwa (Aguilar and Jacobsen, 2003). Growers have also utilized multiple agroecological and physiogeographic zones when growing each year's crop to reduce the possibility of production loss caused by abiotic or biotic stress factors present within a region. Traditional crop cycles tended to last approximately eight to 
ten years, with the first three to four years including potato, then quinoa, beans and another crop (Aguilar and Jacobsen, 2003). The land was left fallow for the next six to seven years and served a number of important purposes. Fallow land was grazed by llama herds that deposited manure, which assisted in the return of indigenous plant species that improved soil fertility and reduced the incidence of pest and disease issues associated with previously planted crops (Aguilar and Jacobsen, 2003).

In the Altiplano of Bolivia and Peru, quinoa seed was traditionally sown in a variety of different ways, including direct seeding in pits, rows, or grooves or simply broadcast. The quinoa planting method was typically based on the location and tools available (FAO, 2011). On a far less common basis in the Inter-Andean valleys, quinoa was sown as transplants to assist in the control of weeds. Production from planting to harvest was undertaken using manual labor (Condori et al., 2015; Aguilar and Jacobsen, 2003).

In different regions of the Bolivian Altiplano, production methods differ in being either fully traditional, a mixture of traditional and mechanized, or completely mechanized depending on growing location and environmental factors, such as soil moisture, temperature and structure. Mechanization has extended quinoa production to previously unused land, and although crop rotations are still utilized by growers, the international demand for quinoa has reduced their duration and complexity (FAO, 2011). When mechanically planted, quinoa is most often sown at a rate of six to eight $\mathrm{kg} \mathrm{ha}^{-1}$ (Condori et al., 2015; FAO, 2011).

Although traditional methods of quinoa production in the Andes focus on hand or mechanical deposition of seed, transplanting quinoa does occur, albeit infrequently. In the Inter-Andean valleys of South America, quinoa transplants have been used by growers to provide a competitive advantage against weeds as well as when grown in a polyculture (Condori et al., 2015; Zimmer,
1996). For example, Quechua farmers of Paucartambo, Peru, have long utilized seedbeds within quinoa nurseries to initially raise quinoa seedlings. Seedlings were then transplanted to the field and intercropped with other desired crops (Zimmer, 1996). Transplants provide quinoa with a developmental head start, and farmers utilize transplants to speed the initially slow growth of quinoa in relation to intercrop species, such as maize. Utilizing quinoa transplants also enabled farmers to sow fewer quinoa plants while still attaining yields similar to a greater number of seeded quinoa plants (Zimmer, 1996).

In the United States and Europe, quinoa production is predominantly mechanized, though it composes only a small portion of worldwide quinoa production (Peterson and Murphy, 2015). Quinoa is seeded directly into soil, with drills usually set to place seed no deeper than 1.0 to $2.5 \mathrm{~cm}$ to ensure emergence (Oelke et al., 1992). Seeding rates and row spacing vary widely depending on the location and environmental conditions present. Seeding rates ranging from 6 to $20 \mathrm{~kg} \mathrm{ha}^{-1}$ have been reported as successful but vary according to the quinoa variety used and soil types present within a specific field (Risi and Galwey, 1991; Darwinkel and Stolen, 1997). Row spacing for quinoa ranges from 20 to $50 \mathrm{~cm}$, with $50 \mathrm{~cm}$ reported as providing the highest yield and most effective weed control (Jacobsen et al., 1994).

In Washington state, the temperate mega-environment west of the Cascade Mountains has been shown to be particularly well suited for quinoa production (Kellogg and Murphy, 2019), due in large part to its cool coastal climates. Susceptibility to heat can be a problematic issue in quinoa (Hinojosa et al., 2018; 2019a), and western Washington generally has lower temperatures and higher humidity than eastern Washington. A majority of this area is heavily populated, with crop production often occurring in urban and peri-urban settings. Equipment, knowledge, and technology for the utilization of transplants in crop production are common in this region, opening the possibility 
of utilizing transplant technology for a relatively novel quinoa crop. The purpose of this study was to test the hypothesis that transplanted quinoa would perform as well as direct-seeded quinoa in terms of crop health, seed yield, and important agronomic characteristics. Therefore, the objectives of this study were to evaluate agronomic differences between the transplant and direct-seeding planting methods across three planting dates and three quinoa varieties.

\section{Materials and Methods}

\section{Location}

The experiment was conducted in the Olympic Peninsula of western Washington state in 2015 and 2016. A 2015 pilot study occurred at Twin Vista Ranch (TVR) on Marrowstone Island (48.039966 $\mathrm{N}$ Lat., $-122.690065^{\circ} \mathrm{W}$ Long.). The location was a privately owned 10.5 ha, smallscale diversified farm focused on livestock, fruit, vegetable, and hay production from 1972 to 2011, prior to becoming a part of the Washington State University (WSU) Jefferson County Extension. The farmland used in this study had previously been planted with broccoli, and the soil type was a Whidbey gravelly sandy loam (loamy-skeletal, isotic, mesic Aquic Dystroxerepts). From April to September 2015, TVR received $87 \mathrm{~mm}$ of precipitation (AgWeatherNet, 2017).

The 2016 trials were located at Finnriver Farm and Cidery (FRF) and Dharma Ridge Farm (DRF). FRF, located in Chimacum, WA $\left(48.009190^{\circ} \mathrm{N}\right.$ Lat., $-122.768686^{\circ} \mathrm{W}$ Long.) is a 13.4 -ha certified organic farm focused on vegetable, berry, and cider apple production. The farmland used in this study had previously been used as an Italian ryegrass/hairy vetch winter cover crop, and the soil type was a San Juan gravelly sandy loam (sandy, isotic, mesic Pachic Ultic Haploxerolls). From April through September 2016, FRF received approximately $112 \mathrm{~mm}$ of precipitation (NOAA, 2017).
DRF, located near Quilcene, WA $\left(47.918998^{\circ} \mathrm{N}\right.$ Lat., $-122.891661^{\circ} \mathrm{W}$ Long.) is a 40.5 -ha certified organic vegetable farm. The farmland used in this study had previously been in mixed vegetable production followed by a winter cover crop of hairy vetch, and the soil type was a Wapato silty clay loam (fine-silty, mixed, superactive, mesic Fluvaquentic Endoaquolls). From April through September 2016, DRF received approximately $125 \mathrm{~mm}$ of precipitation (NOAA, 2017).

\section{Quinoa variety}

Three quinoa varieties, 'Titicaca', 'Red Head' and 'Kaslaea', were chosen based on previous growth and yield success in western Washington. Titicaca is a short-statured quinoa variety with early maturity (Christiansen and Jacobsen, 2016). Red Head is a taller variety that possesses moderate tolerance to pre-harvest sprouting. Kaslaea is intermediate in height with moderate heat tolerance (GRIN, 2015; Hinojosa et al., 2019b).

\section{Planting dates and rates}

In 2015, quinoa was planted at TVR on June 12. Direct-seeded quinoa was planted at a rate of 1.0 $\mathrm{g} \mathrm{m}^{-1}$ with a Jang TD-1 Precision Seeder (Jang Automation Co., Ltd., South Korea). Transplants were grown in $3-\mathrm{cm}^{3}$ cells, filled with Sungro Organic Certified Potting Soil (AFCO Distribution, Spokane, WA), and then transplanted in the field at a rate of 30 seedlings $\mathrm{m}^{-1}$. The 2016 planting dates were 4 April, 23 April, and 6 May and planted in a similar manner as the previous year.

\section{Soil Sampling}

Soil sampling in 2015 occurred on 9 June at TVR to create a baseline understanding of the existing soil nutrient content. A total of 20 subsamples were collected utilizing a $1.59-\mathrm{cm}$ regular slide hammer soil probe (AMS, Inc., American Falls, 
ID) at 0 to $5 \mathrm{~cm}, 5 \mathrm{~cm}$ to $15 \mathrm{~cm}$ and $15 \mathrm{~cm}$ to $30 \mathrm{~cm}$ depths. Subsamples for each depth were mixed into a single plastic sample bag, frozen, and transported to the University of Idaho Analytical Sciences Laboratory in Moscow, ID. The samples were analyzed for nitrate, ammonium, potassium, phosphorus, sulfate, organic matter concentrations, and $\mathrm{pH}$.

Spring soil sampling in 2016 occurred at FRF and DRF on 11 May and followed the same protocol as the 2015 spring soil sampling. At FRF, sampling occurred only at depths of 0 to $5 \mathrm{~cm}$ and $5 \mathrm{~cm}$ to $20 \mathrm{~cm}$ due to the existing hardpan. The 2016 fall soil sampling occurred only at DRF. Subplots were sampled to examine the differences in nutrient use between seeded and transplanted quinoa. Two subsamples were collected from each subplot at a single depth of 0 to $30 \mathrm{~cm}$ using a $1.59-\mathrm{cm}$ regular slide hammer soil probe (AMS, Inc.). Subsamples were mixed to create a single sample for each planting date and planting method combination. Samples were then frozen and transported to the University of Idaho Analytical Sciences Laboratory in Moscow, ID, where they were analyzed for nitrate, ammonium, potassium, phosphorus, sulfate, and organic matter concentrations and $\mathrm{pH}$.

\section{Agronomic trait evaluation}

\section{Emergence and survival}

The 2015 emergence and survival data for TVR were collected on 30 June (19 days after planting), and the 2016 emergence data for FRF and DRF were collected on 7 June (33 days after planting). For plots containing direct-seeded quinoa, a percentage estimating the average overall emergence was observed and recorded. For subplots containing quinoa transplants, counts of surviving seedlings were made to determine average survivability rates.

\section{$\underline{\text { Plant height and growth habit }}$}

In 2015, plant height was recorded at TVR on 30 June, 17 July, 27 July, 4 August, 10 August, and 23 August. Plant height was measured at FRF and DRF every two weeks beginning 26 May and continuing through 30 August. The mean plant height was recorded based on the mean height of three randomly chosen quinoa plants per plot.

The 2015 quinoa growth habit data were collected for TVR on 23 August, and 2016 growth habit data were collected for FRF and DRF on 20 July. According to Jacobsen and Stolen (1993), plants within each plot were rated as having either no branching (NB), some branching (SB), highly branching (HB), or variable branching (V) if the growth habits of plants within the subplot were highly variable.

\section{Lodging}

Percent lodging was evaluated for TVR on 23 August 2015 and for FRF and DRF on 26 July 2016. Multiple data collection dates were the result of differences in maturity and senescence rates of the transplants within each planting date. One 0.25 -m quadrat was used to demarcate the desired sampling area. Quadrats were placed randomly within each subplot after senescence. All plants within a quadrat were cut at the soil level using bypass pruners (AM Leonard, Inc., Piqua, $\mathrm{OH}$ ), bulked, and weighed. Seed was removed from the stem by hand and threshed using a single-head thresher (Precision Machine Co., Inc., Lincoln, $\mathrm{NE}$ ), then separated from the remaining chaff using a $3 / 4-\mathrm{mm}$ sifting screen, processed with a Holland seed blower Ø $200 \mathrm{~mm}$ (Seed Processing Holland, Inc., Salinas, CA), and weighed.

\section{Seed Yield}

Due to wet conditions at harvest in 2015, quinoa plants were harvested prior to full senescence by hand on 26 September and placed in plant dryers 
at $39{ }^{\circ} \mathrm{C}$ for seven days to ensure that all plants were fully dried. Dried quinoa was threshed using a single head thresher (Precision Machine Co., Inc., Lincoln, NE), sifted using a 3/4-mm aluminum sifting screen, and then cleaned using a Holland seed blower Ø $200 \mathrm{~mm}$ (Seed Processing Holland, Inc., Salinas, CA). In 2016, quinoa plants were harvested at maturity for each variety and planting method. Plant date one (PD-T1) transplants were harvested at FRF and DRF on 26 July. Plant date two (PD-T2) transplants at FRF and DRF were harvested on 18 August. For the direct-seeded treatments, plant date one (PD-DS1), two (PDDS2), and three (PD-DS3) and plant date three transplants (PD-T3) were harvested from FRF on 9 September. PD-DS1, PD-DS2, PD-DS3, and PDT3 were harvested from DRF on 11 September. A Vogel Thresher (Bill's Welding, Pullman WA) was used to thresh each subplot. Final processing followed the 2015 protocols.

\section{Experimental design and statistical analysis}

The experiment was a split-plot design with whole plots in randomized complete blocks. In 2015, a single planting date and location were utilized. In 2016, two locations, each including three planting dates, were utilized. The whole plot level consisted of four replications within each plant date, and the split-plot level consisted of subplot combinations of quinoa variety and planting method. Subplots measured $3 \mathrm{~m} \times 1.2$ $\mathrm{m}$ and included three rows of quinoa at $30 \mathrm{~cm} \times$ $30 \mathrm{~cm}$ plant spacing in 2015 and $30 \mathrm{~cm} \times 5 \mathrm{~cm}$ plant spacing in 2016.

Data collected in 2015 and 2016 were run separately using SAS Software (SAS Institute, Cary, NC). A linear mixed model was used and performed with the MIXED procedure in SAS. For 2016 data, fixed effects included location, quinoa variety, planting method, planting date, and their interactions. Random effects included replication nested within location and replication by plant date interaction nested within location.
Correlation across sampling dates within the year was incorporated using a compound symmetry covariance structure. For 2015 data, fixed effects included the planting method, quinoa variety, and their interaction; replication was considered a random effect. Correlation across sampling dates was incorporated using a compound symmetry covariance structure. Pearson correlation coefficients for means of each split-plot were determined using PROC CORR. When performing comparisons, Type 3 fixed effects tests and least squares means were reported. Type 3 fixed effects tests and least squares means were considered significant at $\mathrm{P}<0.05$. A Tukey-Kramer adjustment was used to adjust for multiple comparisons.

\section{Results and Discussion}

\section{Emergence and survival}

In 2015, no difference in emergence percentage was found for variety, planting method, or variety $\times$ planting method $(\mathrm{p}>0.05)$. In 2016, interactions were shown for the plant date $\times$ planting method, location $\times$ planting method, and variety $\times$ planting method. For the planting date $\times$ planting method interaction, PD-T3 had a mean survival rate of 99\%, which was higher than PS-T1 (84\% survival), PD-DS1 (84\% emergence), PD-DS2 (85\% emergence), and PD-DS3 (73\% emergence). PD-DS1, PD-DS2, PD-T1, and PD-T2 also had higher rates of emergence/survival than PD-DS3 (Figure 1). Emergence was higher for direct-seeded quinoa on earlier plant dates and lower on later plant dates. The opposite was true for transplanted quinoa.

Across planting date and variety treatments, the direct-seeded quinoa at DRF had a lower rate of emergence $(71 \%)$ than transplanted quinoa planted at DRF (90\%) and both direct-seeded (90\%) and transplanted (96\%) quinoa at FRF. No difference existed between FRF direct-seeded quinoa, transplanted quinoa, or transplanted quinoa planted at DRF. Differences in emergence/survival were likely caused by excessive levels of precipitation 


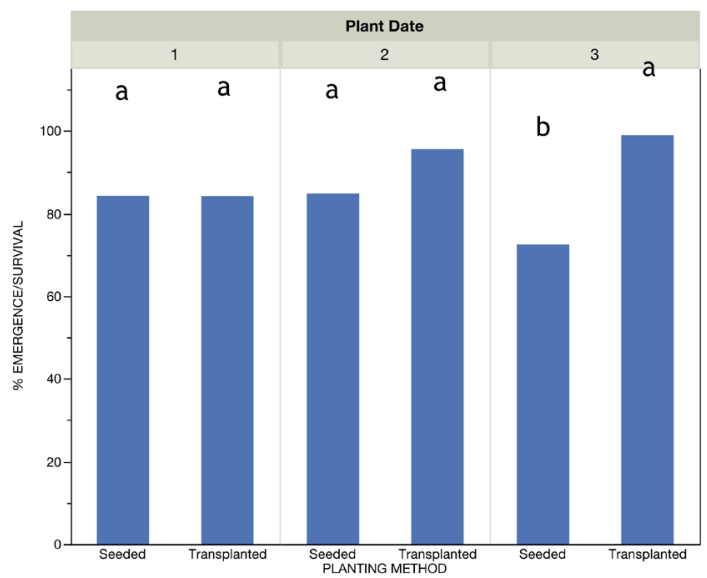

Figure 1. Difference in percent mean emergence/survival by planting date and by planting method interaction in 2016. Different letters indicate significantly different means at $\mathrm{p}<0.05$. Plant Date 1 : 4/4/16, Plant Date 2: 4/23/16, and Plant Date 3: 5/6/16.

experienced at both locations during 2016. Soil conditions at DRF appeared to be more anaerobic and remained higher in soil moisture for longer than those of FRF, which may have contributed to the lower emergence of seeded quinoa via seed rot.

Across planting dates, direct-seeded Red Head (79\%) and Kaslaea (76\%) had lower rates of emergence/survival than transplanted Titicaca (91\%), Red Head (93\%) and Kaslaea (95\%), whereas direct-seeded Titicaca had an emergence rate of $87 \%$ and did not differ from any other variety or planting method combination. This suggests that the speed of emergence observed in Titicaca will be important in the cold and wet western Washington growing conditions.

\section{Plant Height}

In 2015, no difference in plant height was found among varieties across the planting method or between planting methods across quinoa varieties. Furthermore, no interaction existed between quinoa varieties and the planting method $(p>0.05)$. Because the quinoa varieties used contain known differences in plant height, other factors may have caused the observed similarities. The 2015 trial at TVR was planted on June 12, approximately two and a half months after recommended planting times for quinoa (Nurse et al., 2016). It is likely that reduced soil moisture, increased soil and air temperature, as well as fewer growing degree days could have impacted plant development among the three varieties and inhibited typically observed plant heights found for Titicaca, Red Head, and Kaslaea (Walters et al., 2016).

In 2016, a significant plant date $\times$ planting method interaction was found $(\mathrm{p}<0.0001)$. Plants in PDDS1 and PD-DS2 were taller than PD-T1 and PD-T2, whereas plants in PD-T3 $(102 \mathrm{~cm})$ were taller than plants in PD-DS3 $(79 \mathrm{~cm})$. PD-T1 and PD-T2 did not differ in height, nor did PD-DS1 and PD-DS2 (Figure 2).

A variety $\times$ planting method interaction also existed $(p=0.03)$. Red Head had a mean height of $94 \mathrm{~cm}$, which differed from transplanted (63 $\mathrm{cm})$ and direct-seeded $(82 \mathrm{~cm})$ Titicaca. Transplanted Titicaca $(63 \mathrm{~cm})$ was shorter than seeded Titicaca $(82 \mathrm{~cm})$.

Differences were likely the result of growth habits among seeded and transplanted quinoa. Transplanted quinoa tended to undergo higher rates of branching and remain shorter than 
seeded plants, which underwent lower rates of branching and grew to greater heights. Variety differences recorded for plant height also followed expectations.

\section{Growth Habit}

A significant planting method effect existed between transplanted and seeded quinoa for growth habit in $2015(\mathrm{p}<0.0001)$. Quinoa transplants branched at higher rates than direct seeded quinoa $(\mathrm{p}<0.0001)$. Increased branching may have been due to the wide plant spacing utilized because plant spacing has been shown to affect branching in quinoa in a previous study (Risi and Galwey, 1991).

In 2016, a significant plant date $\times$ planting method interaction was found $(\mathrm{p}<0.0001)$. Plants in PD-T1, PD-T2, and PD-T3 all experienced higher rates of branching than plants in PD-DS1, PD-DS2, and PD-DS3. PD-DS1 had less branching than PD-DS2 and PD-DS3. Increased branching in transplanted quinoa could have again been the product of the 30 $\times 30 \mathrm{~cm}$ spacing utilized, which was significantly and more consistently wider than the direct-seeded plant spacing. It is also possible that transplanted quinoa partitioned resources differently than direct-seeded quinoa. In bell peppers, transplants have been shown to devote more nutrients towards reproductive ends, which amounts to greater seed/ fruit production and above-ground biomass (Leskovar and Cantliffe, 1993). In quinoa, a repartitioning of resources would partially occur as an increase in plant branching.

\section{Lodging}

In 2015, lodging was influenced by the planting method ( $\mathrm{p}=0.005)$. Transplanted quinoa (4.7 plants per $\mathrm{m}^{2}$ ) experienced higher numbers of lodged plants per plot than direct-seeded quinoa ( 0.3 plants per $\left.\mathrm{m}^{2}\right)$. Lodging could have been the result of increased branching and seed development associated with transplanted quinoa.

In 2016 , a four-way location $\times$ plant date $\times$ variety $\times$ planting method interaction was found for lodging $(\mathrm{p}=0.03)$. At FRF, Kaslaea, Red Head and Titicaca transplants in PD-1 experienced the highest rates of plant lodging at 15, 14 and 9 plants per $\mathrm{m}^{2}$, respectively, and differed from all other plant date $\times$ variety $\times$ planting method combinations at both FRF and DRF. FRF PD-1 transplanted Kaslaea and Red Head did not differ from each other in lodging rates but did differ from FRF PD-1 transplanted Titicaca.

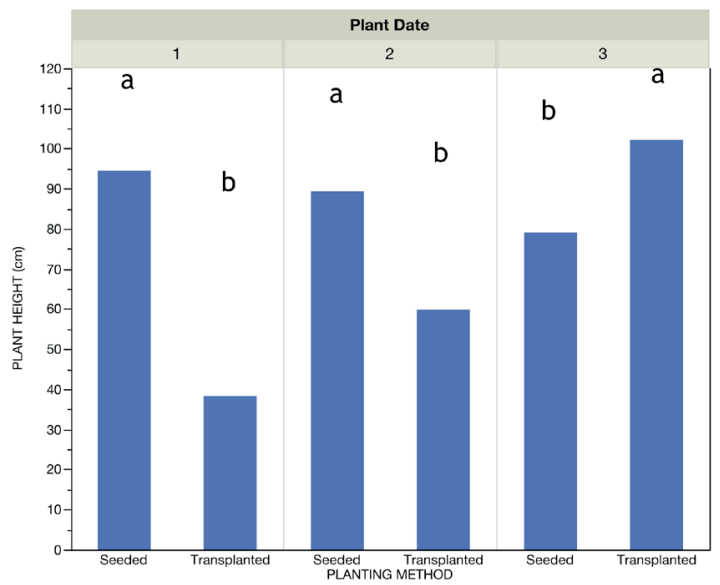

Figure 2. Mean difference in plant height by planting date and by planting method interaction across FRF and DRF locations in 2016. Different letters indicate significantly different means at $\mathrm{p}<0.05$. Plant Date 1: 4/4/16, Plant Date 2: 4/23/16, and Plant Date 3: 5/6/16. 


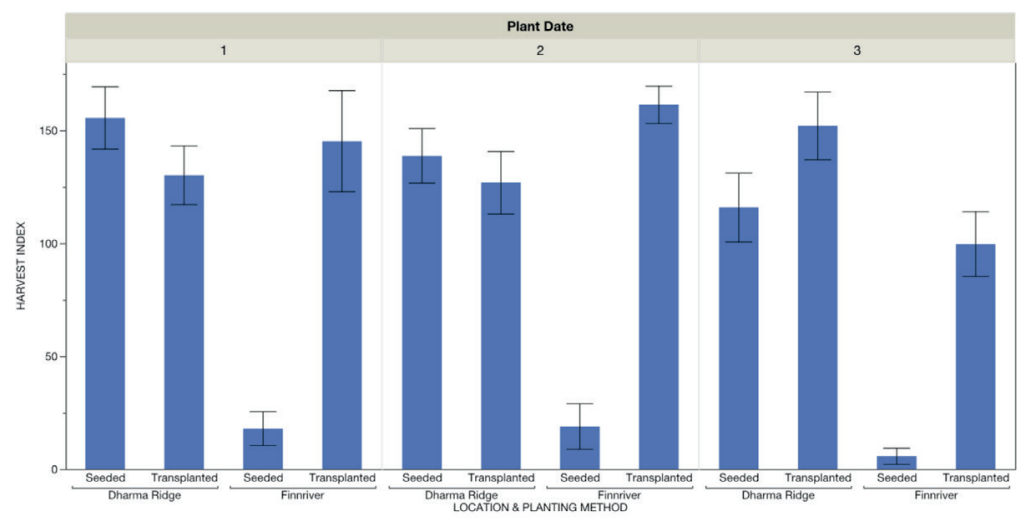

Figure 3. Quinoa seed yield by planting date, by quinoa variety, and by planting method interaction for 2016 .

A significant three-way location $\times$ plant date $\times$ planting method interaction also existed $(\mathrm{p}<0.0001)$. FRF plants in PD-T1 experienced significantly different rates of lodging $\left(12.5\right.$ plants per $\left.\mathrm{m}^{2}\right)$ than DRF plants in PD-T1 (2.7 plants per $\left.\mathrm{m}^{2}\right)$. The FRF PD-T1 lodging rates also differed significantly from FRF quinoa plants in PD-DS2 and PD-DS3, as well as the PD-DS2 plants at DRF. Higher rates of lodging at FRF may have occurred due to the hardpan that existed approximately $20 \mathrm{~cm}$ below the soil surface. The hardpan layer may have hindered root development, and contributed to higher rates of plant lodging when coupled with the more branched growth habit associated with transplants. The higher rates of lodging observed in Kaslaea and Red Head could be attributed to individual variety growth habits. Both are taller varieties than Titicaca, and their increased height, coupled with other factors, may have been responsible for the increased lodging rates (Walters et al., 2016). It is also possible that in allocating greater resources towards reproductive efforts, transplanted quinoa root systems did not develop as extensively as in seeded quinoa, leading to greater rates of lodging. Reduced root development has been noted in transplants of other crops (Leskovar and Cantliffe, 1993).

\section{Soil Analysis}

The 2016 post-harvest soil analyses showed no differences in nitrate, ammonium, phosphorus, potassium, organic matter, or $\mathrm{pH}$ based on plant date or planting method (data not shown). Furthermore, no significant interactions were found between the planting date and the planting method. Differences in nutrient usage by seeded and transplanted quinoa were initially expected. In other crops, such as bell peppers, large differences exist in root development for transplanted and seed plants, with transplants partitioning more resources for reproductive growth and seeded plants allocating more towards root development (Leskovar and Cantliffe, 1993). Based on differences in quinoa plant growth habit and seed yield, it was hypothesized that quinoa transplants would utilize higher amounts of nutrients. It is possible that the lack of difference in nutrient usage can be attributed to unseen root development in seeded quinoa.

\section{Yield}

Transplanted quinoa produced a higher mean yield (3440 kg ha-1) than seeded quinoa (2227 kg ha-1) in $2015(\mathrm{p}=0.001)$ (Figure 3). No difference in yield existed between any of the three varieties in 2015, nor was an interaction found between variety and planting method.

In 2016, a significant three-way location $\times$ plant date $\times$ planting method interaction was found $(\mathrm{p}<0.0001)$. At FRF, quinoa yields in PD-T1 (1845 kg ha-1), PD-T2 (2458 kg ha $\left.{ }^{-1}\right)$, and PD-T3 $\left(2931 \mathrm{~kg} \mathrm{ha}^{-1}\right)$ were not statistically different, nor were yields among direct-seeded quinoa treat- 
ments across all three plant dates. However, a difference did exist between transplanted and seeded quinoa, with transplanted quinoa producing higher yields than seeded quinoa $(\mathrm{p}<0.05)$.

At DRF, the yield of quinoa in PD-T3 $(3607 \mathrm{~kg}$ $\mathrm{ha}^{-1}$ ) was higher than all other transplanted and direct-seeded quinoa in PD-1, PD-2, or PD-3, except quinoa in PD-DS2. The yield for plants in PD-T1 (656 kg ha-1) and PD-T2 (1017 kg ha-1) did not differ statistically from each other. No difference existed in yield for quinoa in PD-DS1, PD-DS2, or PD-DS3.

The harvest index has also been positively associated with seed yield (Bhargava et al., 2007; Pulvento et al., 2010), and transplanted quinoa tended to produce greater seed yields per plant date than seeded quinoa.

At FRF, high amounts of insect damage occurred to the panicle of seeded quinoa plants. Aphids (Aphis spp.) and lygus bugs (Lygus hesperus) attacked newly developing seeds and inflicted sucking damage. Insect feeding damage prevented the formation of quinoa seed on the panicles of many plants and likely contributed to lower seed yields among seeded quinoa at FRF.

A hardpan existed $20 \mathrm{~cm}$ below the soil surface at FRF. The use of machinery for tillage and bed preparation during high soil moisture spring-time conditions and the historical use of the trial ground as a large-scale dairy for over 20 years likely contributed to the creation of the impenetrable soil layer. Seeded quinoa roots may not have been able to penetrate the hardpan and/or find the required nutrients and water, which could have affected seed development and overall seed yield. Regardless of the cause(s), the seeded quinoa at FRF did not yield well, especially compared to the transplanted quinoa.

A three-way plant date $\times$ variety $\times$ planting method interaction was found for yield $(p=0.0002)$. In PD-T1, the yield of Titicaca was lower than Red Head but did not differ from any other variety or planting method combination. The yield of PD-T2 Kaslaea did not differ from PD-T2 Red Head, PD-DS2 Kaslaea, or PD-DS2 Titicaca. The yield of transplanted Titicaca and Red Head, as well as seeded Titicaca, Red Head, and Kaslaea, did not differ. In PD-T3, no difference in yield existed between Titicaca, Red Head, or Kaslaea or between PD-DS3 Titicaca, Red Head, or Kaslaea, although significant variety yield differences did exist across the planting methods used $(\mathrm{p}<0.05)$. Seed yield for Titicaca, Red Head, and Kaslaea in PD-T3 and Kaslaea in PD-T2 produced significantly higher yields than all other plant date/ plant method/variety combinations $(\mathrm{p}<0.05)$. In PD-T3, Titicaca had the highest yield, followed by Kaslaea and Red Head. No other plant date/ variety/planting method combination followed the same pattern, which may be another indication that PD-3 was an optimal time for the planting of all three quinoa varieties as transplants.

In comparison to quinoa yields in other areas of the Pacific Northwest, Canada, and Sub-Saharan Africa, similar or greater yields were achieved in 2015 and 2016 in our trials. Variety trials conducted in Malawi during 2012 utilizing Titicaca, Red Head, and nine other varieties found that Titicaca yielded approximately $653 \mathrm{~kg} \mathrm{ha}^{-1}$ and Red Head yielded $789 \mathrm{~kg} \mathrm{ha}^{-1}$ (Maliro et al., 2017). The Saskatchewan company NorQuin reported quinoa seed yields of $336 \mathrm{~kg} \mathrm{ha}^{-1}$ to greater than 2,242 $\mathrm{kg} \mathrm{ha}^{-1}$ (Guenther, 2014). Lundberg Family farms have reported similar yields of up to 2,242 $\mathrm{kg} \mathrm{ha}^{-1}$, depending on variety and location (North Bay Business Journal, 2016).

\section{Correlations}

The 2015 data analyzed from plant date one at TVR found a number of correlations regarding yield. A strong positive correlation between yield and planting method existed $(\mathrm{r}=0.63 ; \mathrm{p}=0.0009)$. A moderate positive correlation existed between yield and quinoa growth habit $(\mathrm{r}=0.55 ; \mathrm{p}=0.005)$, yield and lodging $(r=0.42 ; \mathrm{p}=0.03)$, and yield and 
plant height $(r=0.48 ; p=0.01)$. Correlations could provide explanation as to why quinoa transplants produced higher seed yields than seeded quinoa in 2015. Transplanted quinoa has a shorter, more extensively branched growth habit than seeded quinoa, which can lead to increased amounts of plant lodging. However, the same characteristics are also associated with increased seed yield because as plants become more branched, they are capable of producing a greater amount of seed per plant.

The 2016 data also showed correlations regarding yield. A weak positive correlation existed between yield and location $(\mathrm{r}=0.20 ; \mathrm{p}=0.01)$, indicating that yield either increased or decreased based on whether the trial occurred at either FRF or DRF. DRF produced higher yields than FRF, which could have been expected based on previous yield trials undertaken by WSU and illustrates the importance of tailoring agronomic solutions to a specific location. A weak positive correlation also existed between yield and plant date $(\mathrm{r}=0.22$; $\mathrm{p}=0.008$ ), indicating that the yield increased as quinoa was planted at later dates. The correlation between yield and plant date may have been weak due to the mixture between seeded and transplanted quinoa planted for each date and the lower yields produced by seeded quinoa as plant dates occurred later in the season. A weak positive correlation existed between yield and planting method $(\mathrm{r}=0.25 ; \mathrm{p}=0.001)$, indicating that when comparing seeded and transplanted quinoa, transplanted quinoa produced higher seed yields.

\section{Conclusion}

The objective of this experiment was to (i) evaluate agronomic differences between seeding and transplanting methods for organic certified quinoa and (ii) determine the possible benefits of utilizing transplanted quinoa over seeding quinoa directly into the soil. In 2015, no significant differences were discovered in terms of emergence/survival or plant height based on planting date, planting method, or quinoa variety. However, significant differences were found between seeded and transplanted planting methods in terms of the time required to reach specific developmental stages, growth habit, plant lodging and yield. Transplanted quinoa reached later developmental stages sooner than seeded quinoa, experienced greater levels of branching and plant lodging, and produced significantly higher seed yields than seeded quinoa. The results also indicated a strong positive correlation between yield and planting method.

In 2016, numerous significant differences were found between transplanted and seeded quinoa regarding plant date, planting method, location, and quinoa variety. Transplanted quinoa averaged higher rates of emergence/survival, reached later developmental stages sooner, set seed in fewer days, and averaged greater seed yields than seeded quinoa within and across the three planting dates utilized. Transplants also experienced greater rates of branching and plant lodging, but lodging rates decreased in later planting dates, signifying that plant date three was an optimal planting time for quinoa transplants. A weak positive correlation between seed yield, planting method, and planting date was also found.

The results illustrate the possibility of using quinoa transplants as an alternative planting method in certified organic quinoa production. The success of later season planting and comparatively high seed yields illustrate another viable option for growers to use when spring-time field conditions are not conducive to planting, when early season crop failures occur, or if a faster maturing crop is desired. The results could also assist in the creation of more diversified crop rotations, which could potentially improve soil nutrient content and reduce pest, disease, and weed issues within a field.

\section{Future Work}

Future research should focus on making the use of quinoa transplants more efficient and accessible 
to growers. Determining the compatibility of quinoa seedlings with mechanical transplantation would perhaps be the most important. A better understanding of appropriate seedling size and hardiness in connection with transplant machinery would enable growers to reduce planting time and effort and help to ensure transplant survival rates once in the field.

Determining the number of transplants required per hectare to achieve yields similar to that of the average seeded quinoa per hectare would also be beneficial. By doing so, the land area and inputs (e.g., seed and fuel) required for quinoa production on a particular farm could be reduced. Requiring less farmland could free space for other uses, such as improving crop rotation or increasing crop diversification.

Research focused on quinoa root development differences between transplanted and seeded quinoa would also provide useful information. Root development work could help explain the faster development and senescence seen in quinoa transplants. Root work would also help determine whether differences in plant development were caused by a head start at planting or if early maturity and senescence are caused by reduced root development or other unknown factors.

Based on the results of another quinoa trial, it may also be worthwhile to investigate the compatibility of quinoa transplants with weeder geese. Work could focus on appropriate spacing required for weeding and reduced damage to quinoa while attaining yields similar to traditionally seeded temperate climate quinoa. More importantly, the use of quinoa transplants could potentially enable geese to enter and weed a quinoa crop within quinoa's critical weed-free period and reduce the need for other methods of weed control.

\section{Resumen}

K. Ludvigson, J.P. Reganold, y K.M. Murphy. 2019. Intensificación sostenible de la producción de quinua en ambientes periurbanos en el oeste del estado de Washington utilizando métodos de trasplante versus métodos de siembra directa. Cien. Agr. 46(2): 100-112. Como un cultivo alternativo en desarrollo tanto en ambientes urbanos como rurales en el Noroeste del Pacífico, la quinua (Chenopodium quinoa Willd.) se siembra predominantemente usando tecnología de siembra directa en granjas de pequeña a gran escala. Sin embargo, la utilización de la metodología de trasplante podría permitir fechas de siembra más tempranas, un mejor control de malezas y una maduración más rápida. Muchos agricultores y jardineros urbanos tienen experiencia y están equipados para utilizar la tecnología de trasplante y podrían adoptar esta práctica con rapidez. Después de un estudio piloto en 2015, se llevó a cabo un experimento en 2016 que comparó el trasplante y la siembra directa en dos granjas en la Península Olímpica del oeste del estado de Washington. Con trasplantes y tratamientos de semillas directas en cada lugar, se plantaron tres variedades de quinua en las fechas de siembra temprana, media y tardía. Aquí, reportamos que la quinua transplantada poseía mayores tasas de supervivencia, era más rápida para alcanzar etapas de desarrollo posteriores y producía mayores rendimientos que la quinua de semilla directa. Los trasplantes fueron más ramificados y más cortos que los de quinua de semillas directas; sin embargo, también experimentaron mayores tasas de hospedaje. A medida que avanzaban las fechas de siembra, el alojamiento disminuyó y el rendimiento de las semillas aumentó en la quinua trasplantada en las tres variedades, en comparación con la quinua de siembra directa. La utilización de trasplantes podría proporcionar a los cultivadores de quinua en entornos urbanos y periurbanos un método de producción mejorado.

Palabras clave: Agricultura periurbana, agroecología, diversidad de cultivos, fecha de siembra, quinua, rendimiento, siembra directa, transplante. 


\section{References}

Aguilar, P.C. and S.E. Jacobsen. 2003. Cultivation of quinoa on the Peruvian Altiplano. Food Reviews International. 19(1-2):31-41.

AgWeatherNet-Washington State University. 2017. Monthly precipitation data for Chimacum, WA. http://weather.wsu.edu/?p=93150. (accessed 12 Jan. 2017).

Bhargava, A., S. Shukla, and D. Ohri. 2007. Genetic variability and interrelationship among various morphological and quality traits in quinoa (Chenopodium quinoa Willd.). Field Crops Research. 101:104-116.

Christiansen, J.L., and S.E. Jacobsen. 2016. Some agronomic strategies for organic quinoa (Chenopodium quinoa Willd.). Journal of Agronomy and Crop Science. 202:454-463.

Condori, B., C. Del Castillo, and M. Garcia. 2015. Agroecological and agronomic cultural practices of quinoa in South America. Chapter 3. John Wiley \& Sons, Inc. Quinoa: Improvement and Sustainable Production. p. 25-45.

Darwinkel, A., and O. Stolen. 1997. Understanding the quinoa crop: Guidelines for growing in temperate regions of northwest Europe. Brussels: European Commission.

FAO. 2011. Quinoa: An ancient crop to contribute to world food security. Regional Office for Latin American and the Caribbean.

Garcia, M. 2003. Agroclimatic study and drought resistance analysis of quinoa for an irrigation strategy in the bolivian altiplano. Dissertationes de Agricultura, $\mathrm{PhD}$ dissertation, Faculty of Applied Biological Sciences, K.U. Leuven, Belgium.

GRIN. 2015. U.S. national plant germplasm system: Ames 13745 (Kaslaea). Germplasm Resources Information Network-ARS. http://www.ars-grin. gov. (Accessed 13 May 2017).

Guenther, L. 2014. Growing quinoa on the prairies. Grainews 40(2):1,4.

Hinojosa, L, J.A. Gonzalez, F.H. Barrios-Masias, F. Fuentes, and K.M. Murphy. 2018. Quinoa abiotic stress responses: A review. Plants 7:106.

Hinojosa, L., J. Matanguihan, and K.M. Murphy. 2019a. Effect of high temperature on pollen morphology, plant growth and seed yield in quinoa. Journal of Agronomy and Crop Science 205:33-45.

Hinojosa, L., N. Kumar, K.S. Gill, and K.M. Murphy. 2019b. Spectral reflectance indices and physiological parameters in quinoa under contrasting irrigation regimes. Crop Science (in press).

Jacobsen, S.E., and O. Stolen. 1993. Quinoa - Morphology, phenology and prospects for its production in Europe. European Journal of Agronomy: the journal of the European Society for Agronomy 2:19-29.

Jacobsen, S.E., I. Jorgensen, and O. Stolen. 1994. Cultivation of quinoa (Chenopodium quinoa Willd.) under temperate climatic conditions in Denmark. Journal of Agricultural Science. 122(1):47-52.

Kellogg, J., and K.M. Murphy. 2019. Evolutionary participatory quinoa breeding for organic agroecosystems in the Pacific Northwest region of the United States, In: Farmer participation in plant breeding: Adapting crops, institutions and policies, Issues in Agricultural Biodiversity Series, Routlege Taylor \& Francis Group.

Leskovar, D.I., and D.J. Cantliffe. 1993. Comparison of plant establishment method, transplant, or direct seeding on growth and yield of bell pepper. Journal of the American Society of Horticultural Science. 118(1):17-22.

Maliro, M.F.A, V.F. Guwela, J. Nyaika, and K.M. Murphy. 2017. Preliminary Studies of the Performance of Quinoa (Chenopodium quinoa Willd.) Genotypes under Irrigated and Rainfed Conditions of Central Malawi. Frontiers in Plant Science 8:227. doi: 10.3389/fpls.2017.00227

Murphy, K.M., J. Matanguihan, F. Fuentes, L. Gomez-Pando, R. Jellen, J. Maughan, and D. Jarvis. 2018. Advances in quinoa breeding and genomics. Plant Breeding Reviews 42:257-320.

NOAA. 2017. Advanced hydrologic prediction service. National Oceanic and Atmospheric Administration. http://water.weather.gov/precip/index. php?location_type $=$ wfo\&location_name $=$ sew\#. (accessed 29 Apr. 2017).

North Bay Business Journal. 2016. Mendocino Co. is part of Lundberg Family Farms' quinoa 
diversification. North Bay Business Journal. https://www.northbaybusinessjournal.com/industrynews/6280248-181/lundberg-ramps-upquinoa-products (accessed 26 May, 2019).

Nurse, R.E., K. Obeid, and E.R. Page. 2016. Optimal planting date, row width, and critical weed-free period for grain amaranth and quinoa grown in Ontario, Canada. Canadian Journal of Plant Science 96:360-366.

Oelke, E.A., D.H. Putnam, T.M. Teynor, and E.S. Oplinger. 1992. Quinoa. Alternative field crops manual. University of Wisconsin Cooperative Extension Service, University of Minnesota Extension Service, Center for Alternative Plant \& Animal Products.

Peterson, A.J., and K.M. Murphy. 2015. Quinoa Cultivation for Temperate North America: Considerations and Areas for Investigation, In: Quinoa: Improvement and Sustainable Production, K.M. Murphy and J.G. Matanguihan, (eds.), WileyBlackwell. Hoboken, New Jersey, USA.
Pulvento, C., M. Riccardi, A. Lavini, R. d'Andria, D. Lafelice, and E. Marconi. 2010. Field trial evaluation of two Chenopodium quinoa genotypes grown under rain-fed conditions in a typical Mediterranean environment in southern Italy. Journal of Agronomy and Crop Science 196:407-411.

Risi, J., and N.W. Galwey.1991. Effect of sowing date and sowing rate on plant development and grain yield of quinoa (Chenopodium quinoa) in a temperate environment. Journal of Agricultural Science 117:325-332.

Walters, H., L. Carpenter-Boggs, K. Desta, L. Yan, J. Matanguihan, and K. Murphy. 2016. Effect of irrigation, intercrop, and cultivar on agronomic and nutritional characteristics of quinoa. Agroecol. Sustain. Food Syst. 40:783-803. doi: 10.1080/21683565.2016.1177805.

Zimmer, K. 1996. Changing Fortunes: biodiversity and peasant livelihood in the Peruvian Andes. Berkeley, Calif.; London: University of California Press. 